\title{
OBITUARY
}

\section{MISS MARGARET WRONG}

Margaret Wrong's sudden death in Uganda on i I April will be felt as a deeply personal loss by a great multitude of all sorts and conditions of men and women, for her sympathies and her friendships, like her interests, were world wide. Her activities in the fields of education, missionary enterprise, and the study of African problems have been described elsewhere; in this Journal it is her services to the Institute and its debt to her which must be recorded, though they cannot easily be assessed. From the early days of the Institute, and soon after she first started her work for Africa, she showed a keen and practical interest in the activities of the Institute and the aims for which it was founded. As a result of her personal efforts a close and fruitful co-operation between the Institute and the International Committee on Christian Literature for Africa was established and has been maintained over a number of years. She took an active part in the linguistic work of the Institute, especially the vernacular essay competitions and the discussions on text-books for African schools. During the war she was one of the small committee which, with Sir Hanns Vischer, kept the Institute in being and directed its activities during those difficult years. After the reorganization in 1944 she became a member of the Linguistic Advisory Committee where her experience of Africa, particularly as regards literacy campaigns and the provision of literature, was invaluable in directing the work of the experts to the service of practical needs.

Her many contacts in Africa and the United States were a means of keeping the staff of the Institute in touch with opinions and personalities in those continents, where she used every opportunity to further the usefulness and extend the range of the Institute's activities. Her wide views, her truly international outlook, and her profound understanding of African problems in their human, political, and scientific aspects, made her help and advice eagerly sought and highly prized. And her response to requests for help from members and staff of the Institute-as to those from all her friends and colleagues-was invariably ready, generous, and practical. Our debt to her cannot be estimated, and our sense of loss can only increase with time. 